\title{
3. COMETARY BRIGHTNESS VARIATIONS AND CONDITIONS IN INTERPLANETARY SPACE
}

\author{
D. A. ANDRIENKO, A. A. DEMENKO, I. M. DEMENKO, \\ and I. D. ZOSIMOVICH \\ Department of Astronomy, Kiev University, Kiev, U.S.S.R.
}

\begin{abstract}
The study of cometary brightness variations can be a good method for determining conditions in interplanetary space. In this work we compare the light curves of comets with curves showing variations in the geomagnetic field at times when the comets are near the ecliptic plane. We have used photometric observations made of 29 comets between 1881 and 1937. It is shown that an increase in the brightness of a comet is associated with an increase in the geomagnetic activity index and consequently with the influence of the solar corpuscular streams and solar wind.
\end{abstract}

It is well known that short-term variations take place in the integral brightness of comets. These variations are also known to be associated with solar activity. The investigation of cometary brightness variations has been described in detail by Vsekhsvyatskij $(1958,1966)$ and Dobrovol'skij (1966), but the processes causing cometary outbursts and brightness variations, and the role of the solar wind and corpuscular radiation, as well as photon solar radiation, are still open for discussion.

This study is an attempt to evaluate the influence of the corpuscular radiation of the Sun on the outbursts observed in the integral brightness of comets. It is known that the disturbances in the magnetic field of the Earth are generally connected with the corpuscular activity of the Sun. The presence or absence of a correlation between the Earth's magnetic activity index and cometary outbursts: will also give an unambiguous answer as to the influence of solar corpuscular radiation upon variations in cometary brightness. To solve the problem we made use of the series of photometric observations of comets listed by Bobrovnikoff (1942), who gave photometric data for a number of comets observed between 1858 and 1937.

The comparison of cometary activity with the geomagnetic activity index was carried out with allowance made for the geometric position of the comet with reference to the ecliptic plane. For each comet the times of nodal passage, the ecliptic latitudes and longitudes during the period of observation and a number of other geometric parameters were computed. The cometary light curves were compared with the geomagnetic activity index, due regard being given to the different ecliptic longitudes of the comets and the Earth. Thus, the moment of each observed cometary outburst was correlated with the geomagnetic field index corresponding to the date for which the same area of the solar surface was visible both from the Earth and the comet. The daily shift in ecliptic longitude was calculated as described by Demenko (1971).

The analysis shows that there is a high correlation between the two processes, especially when the comets were observed near the ecliptic plane. This can easily be seen from the curves shown in Figure 1. The continuous line shows the inter- 
$1001 \mathrm{III}$
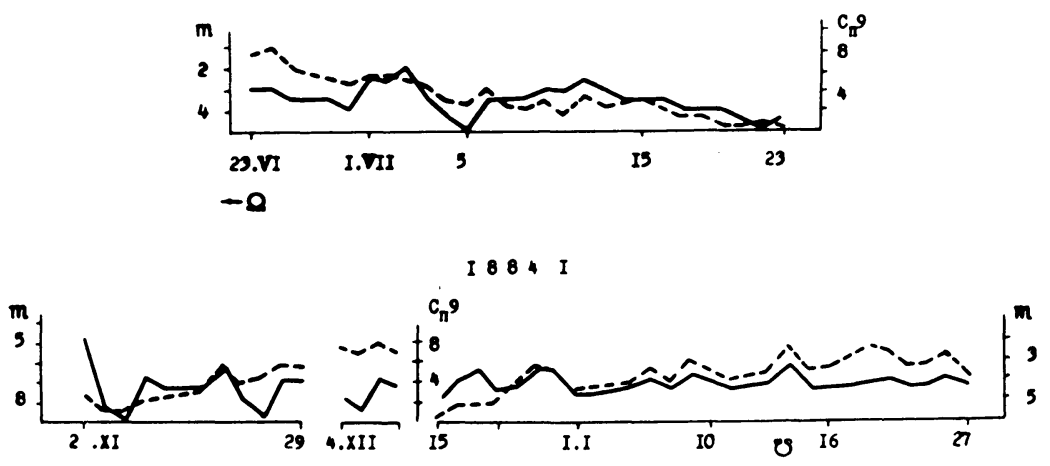

$1886 \mathrm{II}$

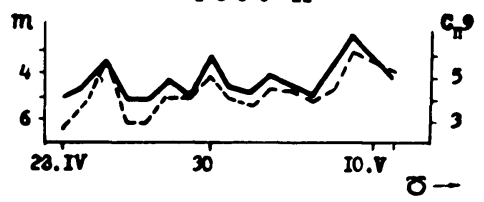

$1886 \mathrm{DX}$

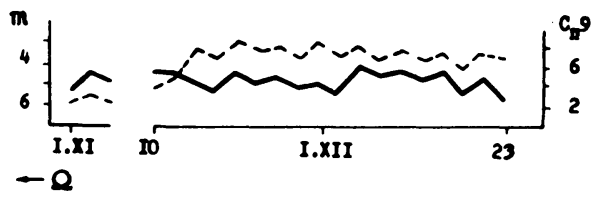

$1900 \mathrm{III}$

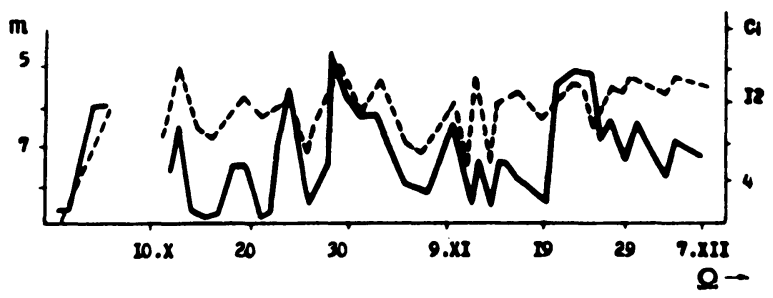

I9IIV

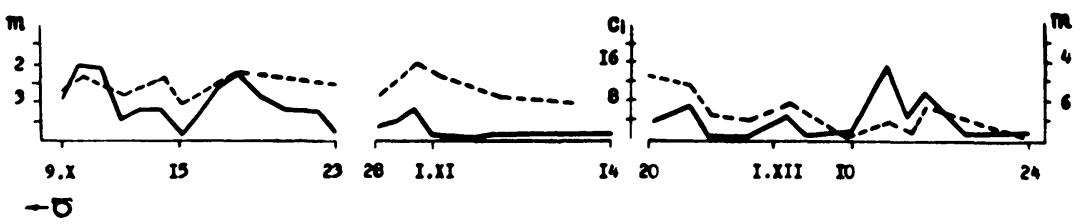

Fig. 1a-f 


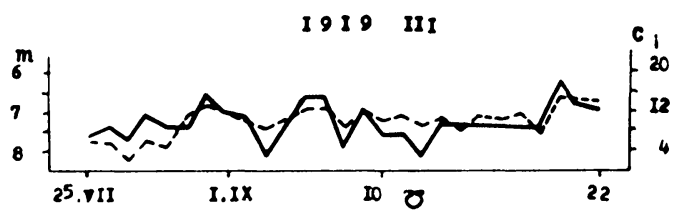

$1921 \mathrm{II}$

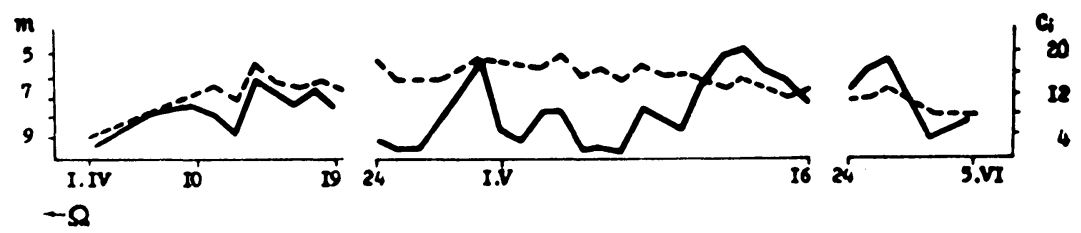

$1930 \mathrm{II}$

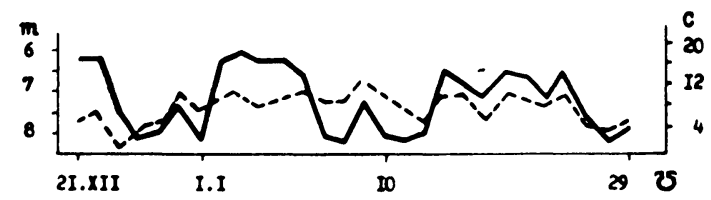

$1930 \mathrm{III}$
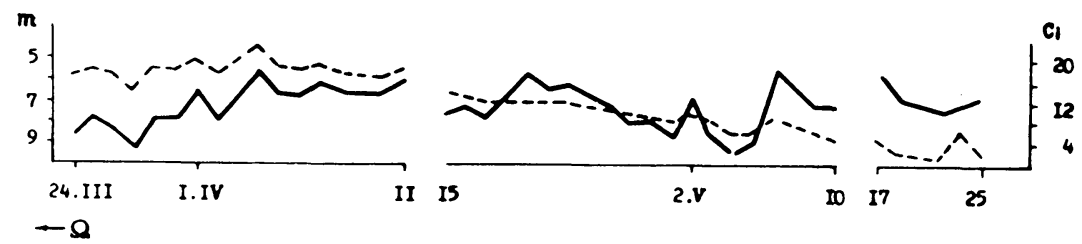

Fig. $1 g_{-j}$

Fig. 1a-j. Correlation of geomagnetic disturbances (solid lines) with brightness variations (broken lines) for ten comets.

national geomagnetic index, since 1890 from Chapman and Bartels (1940) and before then from Zosimovich and Andrienko (1971); the broken line shows the cometary magnitudes, based on Bobrovnikoff's raw data.

The correlation coefficients $r$ and the probability 0.68 and 0.90 confidence intervals for these coefficients, defined as by Shchigolev (1969) and Zajdel' (1968), are given in Table I for the various comets studied. The results show that there is a high correlation $(r=0.8$ to 0.9$)$ when the comets were observed near the ecliptic plane and a decrease in correlation with increasing ecliptic latitude. Figure 2 shows the dependence of the correlation coefficients on ecliptic latitude, the points being obtained by averaging the coefficients in $5^{\circ}$ latitude steps. 
TABLE I

Correlation of cometary brightness variations with geomagnetic activity

\begin{tabular}{|c|c|c|c|c|c|c|c|}
\hline \multirow[t]{2}{*}{ Comet } & \multirow{2}{*}{$\begin{array}{l}\text { Inclination } \\
\text { of orbit to } \\
\text { ecliptic }\end{array}$} & \multirow{2}{*}{\multicolumn{2}{|c|}{$\begin{array}{l}\text { Investigated } \\
\text { latitude } \\
\text { range }\end{array}$}} & \multirow{2}{*}{$\begin{array}{l}\text { Correlation } \\
\text { coefficient }\end{array}$} & \multicolumn{3}{|c|}{ Confidence interval $\sigma_{r}$ for $r$} \\
\hline & & & & & $\begin{array}{l}\text { probability } \\
0.68\end{array}$ & $\begin{array}{l}\text { probability } \\
0.90\end{array}$ & \\
\hline \multirow{2}{*}{$\begin{array}{l}1881 \text { III } \\
1884 \text { I }\end{array}$} & $63^{\circ}$ & $-5^{\circ}$ to & $+36^{\circ}$ & 0.56 & \pm 0.13 & $0.10<\sigma_{r}<$ & 0.18 \\
\hline & 74 & $\begin{array}{l}+80 \\
+45 \\
+17\end{array}$ & $\begin{array}{l}+49 \\
+21 \\
-20\end{array}$ & $\begin{array}{l}0.10 \\
0.22 \\
0.63\end{array}$ & $\begin{array}{l} \pm 0.25 \\
\pm 0.13 \\
\pm 0.15\end{array}$ & $\begin{array}{l}0.20 \\
0.10 \\
0.12\end{array}$ & $\begin{array}{l}0.35 \\
0.18 \\
0.21\end{array}$ \\
\hline \multirow{3}{*}{$\begin{array}{l}1886 \text { II } \\
1886 \text { IX }\end{array}$} & 84 & +70 & +28 & 0.83 & \pm 0.08 & 0.06 & 0.11 \\
\hline & 102 & $\begin{array}{r}+6 \\
+29 \\
\end{array}$ & $\begin{array}{r}+20 \\
+37\end{array}$ & $\begin{array}{l}0.82 \\
0.81\end{array}$ & $\begin{array}{l} \pm 0.15 \\
\pm 0.15\end{array}$ & $\begin{array}{l}0.12 \\
0.12\end{array}$ & $\begin{array}{l}0.21 \\
0.21\end{array}$ \\
\hline & & +43 & +76 & 0.30 & \pm 0.28 & 0.22 & 0.39 \\
\hline \multirow{2}{*}{$\begin{array}{l}1893 \text { II } \\
1899 \text { I }\end{array}$} & 160 & +23 & +29 & 0.32 & \pm 0.22 & 0.16 & 0.28 \\
\hline & 146 & $\begin{array}{l}-33 \\
+33\end{array}$ & $\begin{array}{l}-34 \\
+28\end{array}$ & $\begin{array}{l}0.35 \\
0.35\end{array}$ & $\begin{array}{r} \pm 0.29 \\
\pm 0.29\end{array}$ & $\begin{array}{l}0.23 \\
0.23\end{array}$ & $\begin{array}{l}0.41 \\
0.41\end{array}$ \\
\hline \multirow{2}{*}{$\begin{array}{l}1900 \text { II } \\
1902 \text { III }\end{array}$} & 62 & -1 & +23 & 0.61 & \pm 0.15 & 0.12 & 0.21 \\
\hline & 156 & $\begin{array}{l}+11 \\
+17\end{array}$ & $\begin{array}{l}+17 \\
+24\end{array}$ & $\begin{array}{l}0.44 \\
0.44\end{array}$ & $\begin{array}{l} \pm 0.15 \\
\pm 0.21\end{array}$ & $\begin{array}{l}0.12 \\
0.16\end{array}$ & $\begin{array}{l}0.21 \\
0.28\end{array}$ \\
\hline \multirow{2}{*}{1903 IV } & 85 & +2 & +9 & 0.13 & & & \\
\hline & & $\begin{array}{l}+11 \\
+20\end{array}$ & $\begin{array}{l}+17 \\
+32\end{array}$ & $\begin{array}{l}0.19 \\
0.40\end{array}$ & $\begin{array}{l} \pm 0.15 \\
\pm 0.25\end{array}$ & $\begin{array}{l}0.12 \\
0.20\end{array}$ & $\begin{array}{l}0.21 \\
0.35\end{array}$ \\
\hline \multirow{4}{*}{$\begin{array}{l}1906 \text { VII } \\
1907 \text { IV }\end{array}$} & & +34 & +70 & 0.10 & \pm 0.13 & 0.08 & 0.14 \\
\hline & 56 & +15 & +42 & 0.20 & \pm 0.13 & 0.15 & 0.27 \\
\hline & 9 & $\begin{array}{l}-1 \\
-3\end{array}$ & $\begin{array}{l}-2 \\
-6\end{array}$ & $\begin{array}{l}0.69 \\
0.61\end{array}$ & $\begin{array}{l} \pm 0.22 \\
\pm 0.14\end{array}$ & $\begin{array}{l}0.16 \\
0.12\end{array}$ & $\begin{array}{l}0.28 \\
0.21\end{array}$ \\
\hline & & -6 & -9 & 0.65 & \pm 0.13 & 0.10 & 0.18 \\
\hline \multirow{2}{*}{1908 III } & 140 & +13 & +10 & 0.55 & \pm 0.13 & 0.10 & 0.18 \\
\hline & & & +7 & 0.93 & \pm 0.04 & 0.03 & 0.05 \\
\hline 1911 II & 148 & $\begin{array}{l}+28 \\
+29\end{array}$ & $\begin{array}{l}+30 \\
+17\end{array}$ & $\begin{array}{l}0.20 \\
0.63\end{array}$ & $\begin{array}{l} \pm 0.13 \\
\pm 0.20\end{array}$ & $\begin{array}{l}0.10 \\
0.16\end{array}$ & $\begin{array}{l}0.18 \\
0.28\end{array}$ \\
\hline \multirow[t]{2}{*}{$1911 \mathrm{~V}$} & 34 & $\begin{array}{l}+34 \\
+37\end{array}$ & $\begin{array}{r}27 \\
+27 \\
-18\end{array}$ & 0.32 & \pm 0.25 & 0.20 & 0.35 \\
\hline & & $\begin{array}{l}+27 \\
-22\end{array}$ & $\begin{array}{l}-18 \\
-34\end{array}$ & $\begin{array}{l}0.79 \\
0.32\end{array}$ & $\begin{array}{l} \pm 0.09 \\
\pm 0.25\end{array}$ & $\begin{array}{l}0.07 \\
0.20\end{array}$ & $\begin{array}{l}0.12 \\
0.35\end{array}$ \\
\hline \multirow{2}{*}{1912 II } & 80 & +16 & +49 & 0.44 & \pm 0.20 & 0.16 & 0.28 \\
\hline & 0 & $\begin{array}{l}+50 \\
+78\end{array}$ & $\begin{array}{l}79 \\
+58\end{array}$ & $\begin{array}{l}0.34 \\
0.14\end{array}$ & $\begin{array}{l} \pm 0.19 \\
\pm 0.25\end{array}$ & $\begin{array}{l}0.15 \\
0.20\end{array}$ & $\begin{array}{l}0.27 \\
0.35\end{array}$ \\
\hline \multirow{3}{*}{$\begin{array}{l}1913 \text { IV } \\
1913 \text { VI } \\
1914 \text { II } \\
1914 \mathrm{~V}\end{array}$} & 143 & +30 & +25 & 0.28 & \pm 0.17 & 0.14 & 0.24 \\
\hline & 41 & +5 & +17 & 0.10 & & & \\
\hline & 24 & +10 & +15 & 0.53 & \pm 0.14 & 0.10 & 0.18 \\
\hline \multirow{2}{*}{$1914 \mathrm{~V}$} & 68 & $\begin{array}{r}+14 \\
+29\end{array}$ & $\begin{array}{l}+29 \\
+44\end{array}$ & -0.16 & \pm 0.19 & 0.15 & $\begin{array}{l}0.27 \\
0.18\end{array}$ \\
\hline & 55 & $\begin{array}{l}+29 \\
+20\end{array}$ & $\begin{array}{l}+44 \\
+11\end{array}$ & $\begin{array}{r}-0.46 \\
0.22\end{array}$ & $\begin{array}{l} \pm 0.12 \\
\pm 0.13\end{array}$ & $\begin{array}{l}0.10 \\
0.10\end{array}$ & $\begin{array}{l}0.18 \\
0.18\end{array}$ \\
\hline 1915 II & & +11 & +5 & 0.88 & \pm 0.07 & 0.06 & 0.10 \\
\hline \multirow{2}{*}{$\begin{array}{l}1917 \text { II } \\
1917 \text { III }\end{array}$} & 149 & +21 & +5 & 0.66 & \pm 0.14 & 0.10 & 0.18 \\
\hline & 26 & $\begin{array}{l}+10 \\
+5\end{array}$ & $\begin{array}{l}+5 \\
+1\end{array}$ & $\begin{array}{l}0.04 \\
0.35\end{array}$ & +0.25 & 0.20 & 0.35 \\
\hline \multirow{3}{*}{$\begin{array}{l}1919 \text { III } \\
1921 \text { II }\end{array}$} & 19 & +9 & +17 & 0.56 & \pm 0.13 & 0.10 & 0.18 \\
\hline & 132 & +14 & +36 & 0.66 & \pm 0.13 & 0.10 & 0.18 \\
\hline & & & +4 & 0.30 & & 0.16 & 0. \\
\hline \multirow{4}{*}{$\begin{array}{l}1930 \text { II } \\
1930 \text { III }\end{array}$} & 124 & +55 & +4 & 0.68 & \pm 0.10 & 0.08 & 0.14 \\
\hline & 67 & +30 & +65 & 0.86 & \pm 0.06 & 0.04 & 0.06 \\
\hline & & +59 & +33 & 0.4 & \pm 0.18 & 0.14 & 0.25 \\
\hline & & +27 & +23 & 0.34 & \pm 0.25 & 0.20 & 0.35 \\
\hline \multirow[t]{3}{*}{1936 II } & 79 & +74 & +40 & -0.20 & \pm 0.13 & 0.10 & 0.18 \\
\hline & & +4 & +11 & -0.20 & \pm 0.13 & 0.10 & 0.18 \\
\hline & & & & 0.51 & \pm 0.18 & 0.14 & 0.25 \\
\hline 1937 II & 26 & +20 & +25 & 0.38 & \pm 0.29 & 0.23 & 0.41 \\
\hline 20 & & +25 & +20 & -0.78 & \pm 0.15 & 0.12 & 0.21 \\
\hline $1937 \mathrm{~V}$ & 146 & +27 & +33 & -0.80 & \pm 0.15 & 0.12 & 0.21 \\
\hline & & $\begin{array}{l}+33 \\
+18\end{array}$ & $\begin{array}{l}+22 \\
+15\end{array}$ & 0.31 & \pm 0.14 & 0.10 & 0.18 \\
\hline
\end{tabular}




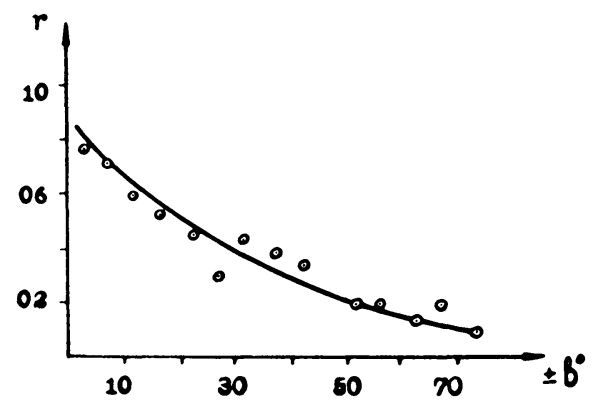

Fig. 2. Dependence of the correlation coefficients $r$ on ecliptic latitude $( \pm b)$.

The correlation of cometary flares with the geomagnetic activity index varies in different parts of the 11-year solar activity cycle. Figure 3 shows the dependence of

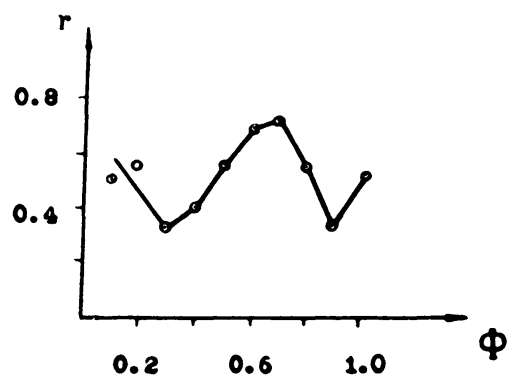

Fig. 3. Variation of the correlation coefficients $r$ during the solar cycle.

the correlation coefficients on the phase of the solar cycle at times when the comets were close to the ecliptic plane. It is clear that the greatest value of $r$ occurs when solar activity is decreasing, and the smallest value falls near solar maximum. This is in good agreement with the hypothesis that the corpuscular streams are most stable when solar activity is decreasing (Zosimovich, 1965). From analysis of the relation between cometary outbursts and disturbances in the geomagnetic field one can arrive at the following conclusions:

(1) Outbursts and variations in integral cometary brightness are closely connected with the solar corpuscular radiation. Cometary activity and changes in the magnetic field should be compared with due regard to the geometric position of the comet. The best results are achieved when a comet is observed at small ecliptic latitudes, because the comet and the Earth are influenced by the same corpuscular structures of the solar corona.

(2) From the correlation coefficients obtained, one can evaluate the angular dimensions of the solar corpuscular streams. From Figure 2 and Table I it follows that the smallest value of $r$ for which the correlation may be considered substantial is 0.35 . 
This brings us to the conclusion that the half-angle of the cone for the latitude dispersion of the corpuscular streams may approach $40^{\circ}$.

(3) It follows from Figure 3 that study of the interaction between the interplanetary plasma and cometary material gives evidence for the stability of the solar corpuscular streams. Despite the fact that the difference in the times of corpuscular interaction between the Earth and a comet may approach two weeks, the correlation coefficients remain rather high. It gives independent proof of the result obtained earlier (Zosimovich, 1965), where the problem of the stability of the streams was investigated by means of geomagnetic data.

(4) Thus, the investigation of cometary brightness variations seems to be very important in connection with the problem of determination both of the geometrical characteristics of the solar corpuscular radiation and of the physical parameters of the solar wind and corpuscular streams at points distant from the Sun and at heliographic latitudes too high for direct measurements to be possible.

(5) The correlation of geomagnetic disturbances with cometary outbursts is best at small heliocentric distances (see Figure 4). The correlation practically vanishes at

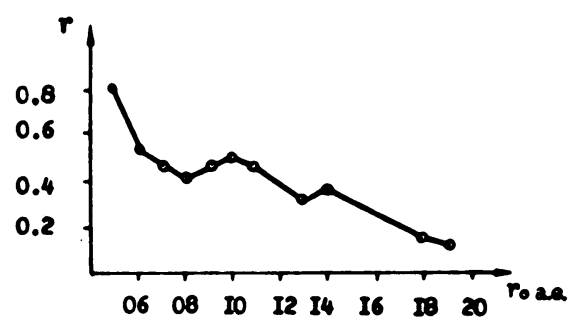

Fig. 4. Dependence of the correlation coefficients $r$ on heliocentric distance $(r \odot)$.

distances exceeding 1.3 AU. This may be explained by the dissociation of corpuscular streams at greater distances from the Sun, where the structure of corpuscular streams seems to change.

\section{References}

Bobrovnikoff, N. T.: 1942, Contr. Perkins Obs. No. 16.

Chapman, S. and Bartels, J.: 1940, Geomagnetism, Oxford, Vol. 2.

Demenko, I. M.: 1971, Probl. Kosmich. Fiz. No. 6.

Dobrovol'skij, O. V.: 1966, Komety, Nauka, Moscow.

Shchigolev, B. M.: 1969, Matematicheskaya Obrabotka Nablyudenij, Moscow.

Vsekhsvyatskij, S. K.: 1958, Fizicheskie Kharakteristiki Komet, Moscow.

Vsekhsvyatskij, S. K.: 1966, Problemy Kometnoj Fotometrii, Inf. Byull. No. 10, 3.

Zajdel', A. N.: 1968, Elementarnye Otsenki Oshibok Izmerenij, Leningrad.

Zosimovich, I. D.: 1965, Geofiz. Astron. No. 8.

Zosimovich, I. D. and Andrienko, D. A: 1971, Probl. Kosmich. Fiz. No. 6. 